\title{
Peculiarities of the Perception of the Lexemes of the Semantic Group «Internal human organs» by Ordinary and Professional Linguistic Consciousness (based on the material of the lexeme heart)
}

\author{
M. V. Shamanova ${ }^{1}$, M. V. Vinogradova ${ }^{1}$
}

${ }^{1}$ P. G. Demidov Yaroslavl State University, 14 Sovetskaya str., Yaroslavl 150003, Russian Federation

DOI: $10.18255 / 2412-6519-2020-2-186-195$

Research Article

Full text in Russian

There is psycholinguistic description of the lexeme heart as a component of the semantic group «Internal human organs» is providing in this article. The associative fields of the lexeme heart were formed on the basis of a free associative experiment. This associative experiment was conducted in two groups of respondents: the doctors, the group of students of a medical university, and students of the humanitarian faculties, who doesn't have medical education. The specificities of the psycholinguistic significance were detected this lexeme in ordinary and professional language consciousness when associative fields, their core and periphery were comparing. The psycholinguistic significance of this lexeme in the two groups is different. The basic meanings, peripheral fields do not match. People who work in medical sphere gave the larger terminological medical vocabulary. It shows the professional awareness of this lexeme by specialists. Psycholinguistic meanings are compared with a generalized lexicographic description. The lexicographic meaning of the lexeme of the heart is wider than the psycholinguistic meaning during the approaches of convergence of the core of the semanthem in the vocabulary descriptions and the results of the experiment. The conclusion was made on the data about the features of the awareness of the lexeme of heart by ordinary and professional language consciousness.

Keywords: linguistic consciousness, free associative experiment, medical vocabulary, semantics, psycholinguistic meaning of the word, lexicographic meaning of the word

INFORMATION ABOUT THE AUTHORS

$$
\begin{array}{c|l}
\begin{array}{c}
\text { Shamanova Marina V. } \\
\text { (correspondence author) }
\end{array} & \begin{array}{l}
\text { E-mail: mshamanova@mail.ru } \\
\text { Doctor of Sciences in Philology, associate Professor, head } \\
\text { of the Department of General and applied Philology }
\end{array} \\
\text { Vinogradova Maria V. } & \text { E-mail: marivinogradova@mail.ru }
\end{array}
$$

Funding: Yarosalvl State University, project VIP-011.

For citation: Shamanova M. V., Vinogradova M. V. Peculiarities of the Perception of the Lexemes of the Semantic Group «Internal human organs» by Ordinary and Professional Linguistic Consciousness (based on the material of the lexeme heart) // Social'nye i gumanitarnye znanija. 2020. Vol. 6, No 2. P. 186-195. (in Russ.) 


\title{
Особенности восприятия лексем семантической группы «Внутренние органы человека» обыденным и профессиональным языковым сознанием (на материале лексемы сердце)
}

\author{
М. В. Шаманова ${ }^{1}$, М. В. Виноградова ${ }^{1}$
}

1Ярославский государственный университет им. П.Г. Демидова, ул. Советская, 14, Ярославль, 150003, Российская Федерация

DOI: $10.18255 / 2412-6519-2020-2-186-195$

УДК 811.161 .1

Научная статья

Полный текст на русском языке

В статье представлено психолингвистическое описание лексемы сердце как компонента семантической группы «Внутренние органы человека». На базе данных свободного ассоциативного эксперимента сформированы ассоциативные поля лексемы сердце в двух группах испытуемых: специалистов-медиков, а также студентов медицинского вуза, и студентов гуманитарных факультетов, не имеющих отношения к медицинскому образованию. При сопоставлении полученных ассоциативных полей, их ядра и периферии, психолингвистического значения были выявлены особенности осмысления данной лексемы обыденным и профессиональным языковым сознанием. Показано, что психолингвистическое значение анализируемой лексемы в двух группах испытуемых не совпадает: различными оказались ядерные значения, состав периферийных значений, терминологическая лексика в большем объеме представлена в качестве реакций в ассоциативном поле медиков, что свидетельствует о профессиональном освоении данной лексемы специалистами. Психолингвистические значения сопоставлены с обобщенным лексикографическим описанием. Выявлено, что лексикографическое значение лексемы сердце оказалось шире психолингвистического при совпадении ядра семантемы в словарных описаниях и результатах эксперимента. На основе полученных данных сделаны выводы об особенностях освоения лексемы обыденным и профессиональным языковым сознанием.

Ключевые слова: языковое сознание, свободный ассоциативный эксперимент, медицинская лексика, семантика, психолингвистическое значение слова, лексикографическое значение слова

ИНФОРМАЦИЯ ОБ АВТОРАХ

\begin{tabular}{r|l} 
Шаманова Марина Владимировна & E-mail: mshamanova@mail.ru \\
(автор для корреспонденции) & Доктор филологических наук, доцент, заведующий \\
& кафедрой общей и прикладной филологии
\end{tabular}

Виноградова Мария Вадимовна | Email: marivinogradova@mail.ru

Финансирование: ЯрГУ, инициативная НИР № ВИП-011.

Для цитирования: Шаманова М. В., Виноградова М. В. Особенности восприятия лексем семантической группы «Внутренние органы человека» обыденным и профессиональным языковым сознанием (на материале лексемы сердце) // Социальные и гуманитарные знания. 2020. Том 6, № 2. С. 186-195.

(C) Шаманова М. В., Виноградова М. В., 2020

Статья открытого доступа под лицензией CC BY-NC-ND (http://creativecommons.org/licenses/by-nc-nd/4.0/) 
Целью данной статьи является психолингвистическое описание лексемы сердце в обыденном и профессиональном языковом сознании и сопоставление его с лексикографическим описанием.

Данная лексема, наряду с другими лексемами - мозг, печень, легкие и др., является частью семантической группы «Внутренние органы человека», которая, в свою очередь, входит в состав медицинской лексики русского языка.

Медицинская лексика в настоящее время активно используется не только в научной литературе, но и в СМИ, разговорной речи. В языкознании данный семантический разряд исследуется в различных аспектах: «комплексное системно-функциональное описание структурно-семантических и семиотических свойств МЛ, проявляющихся в закономерностях ее функционирования, определение основных тенденций развития МЛ» [1], как терминосистема, функционирующая в научных медицинских текстах [2] и в художественной литературе [3], терминосистемы отдельных областей медицинской науки [4; 5; 6; 7], метафорическое использование лексики семантической сферы «Медицина» в текстах СМИ и разговорной речи [8] и т. п.

Как справедливо отмечает Г. А. Абрамова, никакая другая наука не проникает существенными представлениями и понятиями в повседневную жизнь людей в такой степени, как медицина [1].

Для изучения восприятия языковым сознанием - обыденным и профессиональным - нами были отобраны лексемы, функционирующие в русском литературном языке в различных стилях и жанрах, являющиеся нейтральными и общеупотребительными, но в то же время тесно связанные с медицинской лексикой, в частности лексема сердце.

В современной лингвистике существует необходимость разграничения двух типов значений: это значение, которое представлено в толковом словаре, и значение, существующее в сознании носителя языка. Значение слова, представленное в словаре, строится «в соответствии с принципом редукционизма, т. е. минимизации признаков, включаемых в значение», «лексикографическое значение - это в любом случае искусственный конструкт лексикографов, некоторый субъективно определенный ими минимум признаков» [9, с. 57]. И. Г. Овчинникова следующим образом разграничивает лексикографическое и психолингвистическое значения: «Под лексикографическим значением подразумевается словарное толкование, под психолингвистическим - интерпретация экспериментальных данных, позволяющая установить смыслы, связанные со словом в языковом сознании» [10, с. 261]. В связи с этим представляется интересным обратиться к психолингвистическому значению слова. По результатам свободного ассоциативного эксперимента психолингвистическое значение слова наиболее точно отражает языковую картину сознания носителя языка. Это дает возможность представить содержание слова как некоторую психологическую реальность.

Для определения психолингвистического значения лексемы сердце нами был проведен свободный ассоциативный эксперимент.

Испытуемым предлагалось следующее задание:

«Прочитайте предложенный список слов и около каждого напишите первое слово, которое придет в голову.

Мозг -

Печень - 
Сердце -

Легкие -

Почки -

Желудок -

Укажите, пожалуйста, свои данные: пол: возраст __.."

Для студентов мы просили указывать дополнительные данные: вуз, курс, факультет.

В эксперименте приняли участие 210 человек. Среди них - люди, которые по роду своей деятельности связаны с медициной, работают в медицинской сфере, обучаются в медицинских вузах (105 испытуемых). Остальные - студенты гуманитарных факультетов, испытуемые, которые не связаны с медициной и никогда не работали в данной сфере (105 испытуемых).

По результатам эксперимента были составлены ассоциативные поля лексемы сердце в непрофессиональном и профессиональном языковом сознании.

\section{Ассоциативное поле лексемы «сердце» в обыденном языковом сознании}

СЕРДЦЕ 105 - любовь 20, подруга 10, боль, чувство 9, душа, мотор 7, бьется, насос 6, ритм 4, горячее, красное, кулак, мышца 3, жизнь, рисунок, стук 2, аритмия, артерии, грудная клетка, дума, камень, капилляр, кровоток, орган, сосуды 1.

Всего 105 реакций, из них различных - 25. Отказов нет.

Для формулирования психолингвистического значения лексемы сердце сходные семы были нами обобщены, и данное значение сформулировано как связное перечисление обобщенных семантических компонентов.

\section{СЕРДЦЕ}

1. Чувства человека 9, его душа 7, способность любить 30, испытывать боль 9. Всего 55 реакций.

2. Мышечный 3 орган 1, размером с кулак 3 красного цвета 3 в грудной клетке 1 , который бьется 6 в определенном ритме 4, стучит 2, работает как мотор 7 , насос 6 , обеспечивает кровоток 4 , дает жизнь 2 , нарушение работы которого приводит к аритмии 1 , вызывает боль 9 . Всего 52 реакции.

3. Душевные качества, характер человека 3. Горячее сердце. Всего 3 реакции.

4. Рисунок 2. Всего 2 реакции.

Были выявлены реакции, которые не могут быть интерпретированы однозначно и требуют уточнения при проведении других экспериментов или верификации результатов проведенного свободного ассоциативного эксперимента: дума 1 , камень 1.

\section{Ассоциативное поле лексемы «сердце» в профессиональном языковом сознании}

СЕРДЦЕ 105 - любовь 21, жизнь 12, кровь 11, мотор 9, инфаркт 8, кровообращение, насос 5, душа, экг 3, биение, клапан, чувство 2, артериальная гипертензия, бычье, бьется, главный орган живого организма, давление, дилатация, еда, капча, 
коронарные артерии, лево, легкие, механизм, мышца, работа, ранение, ритм, сосуд, стол, собака, трудяга, частота сердечных сокращений, человек 1.

Всего 105 реакций, из них различных - 34. Отказов нет.

Для формулирования психолингвистического значения лексемы сердце сходные семы были нами обобщены, и данное значение сформулировано как связное перечисление обобщенных семантических компонентов.

\section{СЕРДЦЕ}

1. Главный мышечный 1 орган 1 живого организма 3, который бьется 3, работает 2 в определенном ритме 2, нагнетает кровь 11 через клапаны 2 и обеспечивает кровообращение 5 по сосудам 2, работает как мотор 9, насос 5, механизм 1, дает жизнь 12, нарушение работы которого может быть вызвано ранением 1, приводит к инфаркту 8, артериальной гипертензии 2, дилатации 1. Расположен между легкими 1, смещен влево 1. Методом обследования работы сердца является ЭКГ 3. Всего 76 реакций.

2. Чувства 2 человека 1, его душа 3, способность любить 21. Всего 27 реакций.

3. Еда 1, приготовленная из этого органа некоторых животных 1. Всего 2 реакции.

4. Рисунок 1. Всего 1 реакция.

Неинтерпретируемая реакция - стол 1.

Сравним освоение лексемы сердце в обыденном и профессиональном языковом сознании.

Сопоставление ассоциативных полей двух групп испытуемых показывает следующее. Ядерная реакция в двух ассоциативных полях совпадает: любовь 21. На втором месте у испытуемых, не имеющих медицинского образования, располагается реакция подруга 10, а у медиков - жизнь 12, что демонстрирует особенности восприятия лексемы специалистами и неспециалистами. Кроме того, особенности освоения данной лексемы, на наш взгляд, выражаются в реакциях, данных исключительно испытуемыми одной группы (сходные семантические реакции были обобщены). Так, испытуемыми с немедицинским образованием были даны реакции: подруга 10, боль 9, горячее 3, красное 3, кулак 3, стук 2, аритмия 1, артерии 1, грудная клетка 1, камень 1, капилляр 1. Среди несовпадающих реакций у неспециалистов преобладают «немедицинские» реакции, из терминов в качестве единичных реакций встречаются четыре: аритмия, артерии, грудная клетка, капилляр. Исключительно медицинскими работниками или студентами, получающими медицинское образование, были даны следующие реакции: кровь 11, инфаркт 8, экг 3, клапан 2, артериальная гипертензия 1, бычье 1, давление 1, дилатация 1, еда 1, коронарные артерии 1, лево 1, легкие 1, механизм 1, работа 1, ранение 1, собака 1, трудяга 1, частота сердечных сокращений 1, человек 1. Реакции специалистов носят более дифференцированный характер. Высокий индекс яркости имеют реакции, непосредственно связанные с медициной (кровь 11, инфаркт 8), 53 \% реакций, данных исключительно медиками, относятся к терминологической лексике: инфаркт, ЭКГ, клапан, частота сердечных сокращений и др. Интересен тот факт, что метафорические реакции в двух группах испытуемых совпадают: мотор (индекс яркости 7 у неспециалистов и 9 у специалистов), насос (индекс яркости 6 и 5 соответственно). 
Психолингвистические значения не совпадают в двух группах испытуемых. Различными по яркости являются ядерные значения. В обыденном языковом сознании первым в структуре семантемы выступает значение 'чувства человека', хотя разрыв между первым и вторым значением - 'орган кровообращения' - небольшой (3 реакции). В профессиональном языковом сознании ядерным значением с индексом яркости, намного превышающим последующие, является значение 'главный орган кровообращения живого организма' (индекс яркости 76; ср.: значение 'чувства человека' имеет индекс яркости 27). Третье значение, имеющее низкий индекс яркости, не совпадает в группах испытуемых: 'душевные качества, характер человека' в обыденном языковом сознании и 'еда' в профессиональном языковом сознании. И последнее, четвертое значение, представлено единичными реакциями у специалистов и неспециалистов.

Таким образом, можно говорить о различном восприятии языковым сознанием специалистов и неспециалистов лексемы сердце.

С целью сопоставления психолингвистического и лексикографического значения нами было составлено обобщенное лексикографическое описание лексемы сердце на основе ряда словарей. Словарные дефиниции различных словарей могут существенно отличаться друг от друга. Для наиболее полного лексикографического описания значения слова исследователи используют принцип дополнительности словарных дефиниций, который заключается в том, что «каждая из дефиниций разных словарей отражает некоторые существенные признаки значения, но наиболее полное описание осуществляется лишь совокупностью дефиниций разных словарей, которые дополняют друг друга» [цит. по: 11, с. 5]. Методика обобщения словарных дефиниций изложена в [12, с. 19-21; 13; 14].

Нами были использованы следующие основные этапы алгоритма обобщения словарных дефиниций: 1) выписываются значения исследуемого слова из всех доступных словарей; 2) составляется единый список всех значений исследуемого слова, зафиксированных в разных словарях; 3) «уточняется полученный на предыдущем этапе список значений исследуемого слова по денотативному принципу: если слово номинирует некий денотат, отличный от других денотатов, фиксируется отдельное значение»; 4) анализируются примеры, приводимые в дефинициях словарных статей разных словарей, на основе иллюстративного материала уточняются имеющиеся и выявляются новые значения; 5) «формулируется обобщающая дефиниция значения исследуемой единицы в виде расширенного набора сем с учетом всех семантических компонентов и лексикографических помет, выделенных несовпадающими дефинициями разных словарей» [11, с. 13-16].

Для обобщенного словарного описания лексемы сердце нами были использованы толковые словари второй половины-конца XX века и новейшего периода $[15 ; 16 ; 17 ; 18]$.

В «Словаре русского языка» под ред. А. П. Евгеньевой [15] дается следующее определение лексемы сердце (иллюстративный материал приведен в сокращении, не приведены грамматические пометы).

СЕРДЦЕ 1. Центральный орган кровообращения в виде мускульного мешка, находящийся у человека в левой стороне грудной полости. Он слушает во всех местах грудь и говорит, что дыхание решительно чистое, что биение сердца весьма правильное. Чернышевский, Дневник моих отношений с тою, которая теперь состав- 
ляет мое счастье. || Место на левой стороне груди, где находится этот орган. Прижать руки к сердиу. 2. Этот орган как символ средоточия чувств, переживаний, настроений человека. Сердце радуется. || Этот орган как символ отзывчивости, доброты. - У вас не хватит сердца, если вы начнете жалеть всех нас. М. Горький, Мать. || Этот орган как символ любовных чувств, любовной привязанности, склонности. Отдать свое сердце кому-л. 3. перен. Душевный мир человека, его переживания, настроения, чувства. Сердце, как и ум, требует развития. И. Гончаров, Воспоминания. || c определением. Душевные качества, характер человека. - У меня, должно быть, сердце черствое. Тургенев, Новь. || с определением. Человек как носитель определенных душевных качеств, характера. Оно было с ним, походное братство, верность простых сердец, дружба которых не нарушится вовеки. Саянов, Небо и земля. 4. перен. Разг. Гнев, раздражение. - Молчи, баба! - с сердцем сказал Данило. - С вами кто свяжется, сам станет бабой. Гоголь, Страшная месть. 5. перен. Центр, главная часть чего-л. Середину площадки, самое видное место, занимала постройка насосной станции - сердце всего нефтепровода. Ажаев, Далеко от Москвы.

В словаре С. И. Ожегова [16] приведено меньшее количество значений, не указываются «оттенки значений»:

СЕРДЦЕ 1. Центральный орган кровеносной системы в виде мышечного мешка (у человека в левой стороне грудной полости). С. бъется. Порок сердца. 2. neрен. Этот орган как символ души, переживаний, чувств, настроений. Доброе, чуткое, отзывчивое с. 3. перен. Важнейшее место чего-н., средоточие. Москва - с. нашей Родины. 4. Символическое изображение средоточия чувств в виде вытянутого по бокам овала, мягко раздвоенного сверху, книзу сужающегося и заостренного. $C$., пронзенное стрелой.

Объем семантемы в «Большом толковом словаре русского языка» под ред. С. А. Кузнецова [17] значительно расширен:

СЕРДЦЕ 1. Центральный орган кровообращения в виде мускульного мешка, находящийся у человека в левой стороне грудной полости. Здоровое, больное с. у кого-л. Молодое с. Учащённый ритм сердца. Ангина даёт осложнение на с. В с. прослушиваются шумы. Порок сердца. // Место на левой стороне груди, где находится этот орган. Выстрелить, попасть в с. Хвататься за с. / Символ отзывчивости, доброты. Нет у тебя сердца. Сердца не хватит жалеть всех. / Символ любовной привязанности, склонности. Растревожил ты мне с. своим появлением! Покорить чьё-л. с. 2. Такой орган некоторых животных. Говяжье, свиное с. Отварное с. 3. Внутренний мир человека (сфера эмоций, интуиции и т. п.; обычно в противопоставлении рассудку, разуму; душа). Трогать, потрясать, зажигать с. зрителей. Надрывать чьё-л. с. 4. (c onp.). Душевные качества, характер человека (о человеке с такими качествами, характером). Верное, преданное, доброе, чёрствое, отважное, трусливое c. 5. Разг. Гнев, раздражение, злоба. Ругнуться в сердцах (в таком состоянии). Держать с. на кого-л. 6. Центр, главная часть чего-л. С. города. Проникнуть в сердце неприятельского тыла.

В «Большом универсальном словаре русского языка» под ред. В. В. Морковкина [18] дается следующее толкование (знак $\bigcirc$ указывает на пассивный лексикосемантический вариант слова):

СЕРДЦЕ 1.0. Центральный орган кровообращения у человека и животных в виде мускульного мешка с несколькими полостями (камерами), находящегося в грудной клетке (у человека - слева). Здоровое сердце. 1.0.1. разд. Боль в этом 
органе, а ткж. болезнь этого органа. Лекарство от сердца. О1.1. Этот орган некоторых животных как продукт питания, а ткж. кушанье из него. Отварное с. 1.2. Место на левой стороне груди человека, где располагается этот орган. Метить в сердце. 2.0. Этот орган, понимаемый как средоточие душевных качеств, черт, характеризующих личность человека, его характер. Син. душа. Доброе сердце. 2.1. Этот орган, понимаемый как источник доброты, отзывчивости. У тебя нет сердца. 2.2. Этот орган как источник и средоточие любовных чувств, переживаний. Oтдать кому-л. свое с. 2.3. с определением. Человек как носитель каких-л. качеств, черт характера. Чистое с., она все приняла на веру. 3.0. Этот орган как средоточие чувств, настроений, переживаний человека, как символ его внутреннего мира. Син. душа. Человеческое сердце. 4.0. Символическое изображение этого органа (прежде всего как знака любовных чувств) в виде вытянутого по бокам овала, мягко раздвоенного вверху и заостренного внизу. Кулон в виде сердца. 5.0. перен. Гнев, раздражение (связано с тем, что сердце в древности считалось вместилищем гнева). Унять с. 6.0. перен. Центр, главная часть чего-л. Москва - с. России.

Таким образом, во всех проанализированных словарях представлено разное количество семем в семантеме слова сердце. В соответствии с указанной выше методикой было сформулировано обобщенное лексикографическое описание лексемы сердце.

СЕРДЦЕ 1. Центральный орган кровообращения у человека и животных в виде мускульного мешка с несколькими полостями (камерами), находящийся у человека в левой стороне грудной полости. Пациент жалуется на боли в сердце. 2. перен. Этот орган как символ души, чувств, переживаний, настроений человека (символ отзывчивости, доброты, любовных чувств и т. п.), внутренний мир человека. Сердце у него нежное, детское. 3. Место в левой стороне груди, где находится этот орган. Схватиться за сердце. 4. Такой орган некоторых животных как продукт питания, а также кушанье из него. Приготовить говяжье сердце на ужин. 5. перен. (с опр.). Душевные качества, характер человека (о человеке с такими качествами, характером). Эта история тронула мое сердце. 6. перен. Разг. Гнев, раздражение, злоба. 7. перен. Важнейшее место, имеющее существенное значение для чего-н., средоточие чего-н. Этот центр управления - сердце всей системы. - 8. Символическое изображение органа (прежде всего как знака любовных чувств) в виде вытянутого по бокам овала, мягко раздвоенного сверху, книзу сужающегося и заостренного. С., пронзенное стрелой.

Сопоставление психолингвистических значений в двух группах испытуемых и обобщенного лексикографического описания показало, что эти значения не совпадают. Лексикографическое описание значительно шире психолингвистического. При обобщенном словарном описании многозначное слово сердце включает 8 значений, психолингвистическое значение данной лексемы в обыденном и профессиональном языковом сознании включает 4 значения, два из которых представлены единичными реакциями. Следует отметить, что в «Большом универсальном словаре русского языка» под ред. В. В. Морковкина лексико-семантический вариант 'орган как источник и средоточие любовных чувств, переживаний' является пассивным [18], что не подтверждается экспериментальными данными (ср. реакции сnособность любить 30 в обыденном языковом сознании и любовь 21 у медиков), поэтому обобщенное второе лексикографическое значение, на наш взгляд, составляет ядро семантемы сердце. Таким образом, ядерные значения в семантеме слова 
при лексикографическом описании подтверждаются психолингвистическим описанием: 1. Центральный орган кровообращения у человека и животных в виде мускульного мешка с несколькими полостями (камерами), находящийся у человека в левой стороне грудной полости. 2. перен. Этот орган как символ души, чувств, переживаний, настроений человека (символ отзывчивости, доброты, любовных чувств и т. п.), внутренний мир человека.

При психолингвистическом описании оказались неактуализированными следующие значения: 'место в левой стороне груди, где находится этот орган'; 'гнев, раздражение, злоба'; 'важнейшее место, имеющее существенное значение для чегон., средоточие чего-н.'. Значение 'символическое изображение органа (прежде всего как знака любовных чувств) в виде вытянутого по бокам овала, мягко раздвоенного сверху, книзу сужающегося и заостренного' несколько трансформируется в языковом сознании и представлено обобщенными реакциями рисунок.

Таким образом, на основании проведенного сопоставления психолингвистического значения лексемы сердце в двух группах испытуемых и сопоставления психолингвистического описания с лексикографическим можно сделать следующие выводы:

1. Психолингвистическое значение анализируемой лексемы в двух группах испытуемых не совпадает: различными оказались ядерные значения, состав периферийных значений, терминологическая лексика в большем объеме представлена в качестве реакций в ассоциативном поле медиков, что свидетельствует о профессиональном освоении данной лексемы специалистами.

2. Лексикографическое значение в данном исследовании оказалось шире психолингвистического при совпадении ядра семантемы в словарных описаниях и результатах эксперимента.

\section{Ссылки / References}

1. Абрамова Г. А. Медицинская лексика: основные свойства и тенденции развития: дис. ... д-ра филол. наук. Краснодар, 2003. 312 с.

2. Буданова Н. А. Развитие медицинской терминологии в русском литературном языке второй половины XIX века (на материале названий болезней): автореф. дис. ... канд. филол. наук. Тверь, 2018. 19 с.

3. Жидкова Ю. Б. Функционирование медицинской терминологии в художественных произведениях русских писателей XIX-начала XXI веков: на материале прозы А. П. Чехова, В. В. Вересаева, М. А. Булгакова, Ю. П. Германа, В. П. Аксенова, Л. Е. Улицкой: автореф. дис. ... канд. филол. наук. Воронеж, 2008. 25 с.

4. Макаренко Е. Д. Когнитивно-деривационный потенциал хирургической терминологии: автореф. дис. ... канд. филол. наук. Краснодар, 2008. 22 с.

5. Маслова Н. Н. Структурно-семантический анализ и системность составных терминов кардиологии и пульмунологии: наименования болезней и патологических процессов: автореф. дис. ... канд. филол. наук. СПб., 2007. 24 с.

6. Смирнова Е. В. структурно-семантический и лексикографический аспекты медицинской терминологии: на примере кардиологической лексики: автореф. дис. ... канд. филол. наук. Ярославль, 2012. 24 с. 
7. Трафименкова Т. А. Терминология болезней как объект ономасиологического, семантико-парадигматического и лексикографического исследования: автореф. дис. ... канд. филол. наук. Орел, 2008. 21 с.

8. Пикалова Е. В. Медицинская лексика в метафорическом использовании: автореф. дис. ... канд. филол. наук. Воронеж, 2013. 26 с.

9. Стернин И. А. К разработке психолингвистического словаря // Вопросы психолингвистики. 2010. № 2 (12). С. 57-63.

10. Овчинникова И. Г. Диалог субкультур (концепты деньги и бизнес в сознании молодых россиян) // Я и другой в пространстве текста. Пермь-Любляна, 2009. Вып. 2. C. 256-280.

11. Стернин И. А., Рудакова А. В. Словарные дефиниции и семантический анализ. Воронеж: Истоки, 2017. 34 с.

12. Стернин И. А., Рудакова А. В. Психолингвистическое значение слова и его описание. Теоретические проблемы. Lambert Academic Publishing: Saarbrücken, 2011. 192 c.

13. Рудакова А. В. О понятии интегрированного лексикографического значении слова и методике его описания // Культура общения и ее формирование: межвуз. сб. науч. тр. / Под ред. И. А. Стернина. Воронеж: Истоки, 2015. Вып. 31. С. 109-115.

14. Рудакова А. В. Психолингвистическое и лексикографическое значения слова: что шире и объемнее? // Лингвоконцептология и психолингвистика: сб. науч. статей / Научн. ред. И. А. Стернин. Воронеж: Истоки, 2013. Вып. 6. С. 58-72.

15. Словарь русского языка: В 4-х т. / РАН, Ин-т лингвистич. исследований; под ред. А. П. Евгеньевой. 4-е изд., стер. М.: Рус. яз.; Полиграфресурсы, 1999. Т. 4. С-Я. 797 c. URL: http://feb-web.ru/feb/mas/mas-abc/default.asp (дата обращения: 30.04.2020)

16. Ожегов С. И. Толковый словарь русского языка. М.: ООО Издательство «Мир и образование»: 000 Издательство Астрель»: 000 «Издательство «Оникс», 2012. 1376 с.

17. Большой толковый словарь русского языка / Гл. ред. С. А. Кузнецов. СПб.: Норинт, 2014. 1536 c.

18. Морковкин В. В. Богачева Г. Ф., Луцкая Н. М. Большой универсальный словарь русского языка / Под ред. В. В. Морковкина. М.: Словари XXI века; АСТ-ПРЕСС ШКОЛА, 2016. $1456 \mathrm{c}$. 